\title{
NOTES
}

${ }^{1}$ Wesley Salmon, "Should We Attempt to Justify Induction?" Philosophical Studies, 8:33-48 (April 1957).

${ }^{2}$ Max Black, Problems of Analysis (Ithaca: Cornell University Press, 1954), Pp. 157225.

${ }^{3}$ Hans Reichenbach, The Theory of Probability (Berkeley: University of California Press, 1944). Reichenbach states his rule of induction as follows: "If an initial section of $\mathrm{n}$ elements of a sequence $\mathrm{x}_{1}$ is given, resulting in the frequency $\mathrm{f}^{\mathrm{n}}$, and if, furthermore, nothing is known about the probability of the second level for the occurrence of a certain limit $p$, we posit that the frequency $\mathrm{f}^{1}$ (i $\supset \mathrm{n}$ ) will approach a limit $p$ within $\mathrm{f}^{\mathrm{n}} \pm \delta$ when the sequence is continued." (Pp. 446.) Reichenbach goes on to say, "The posit $\mathrm{f}^{\mathrm{n}}$ is not the only form of anticipative posit. We could also use a posit of the form $\mathrm{f}^{\mathrm{n}}+\mathrm{c}_{\mathrm{n}}$ where $\mathrm{c}_{\mathrm{n}}$ is an arbitrary function, which is chosen that it converges to 0 with $\mathbf{n}$ increasing to infinite values. All posits of this form will converge asymptotically towards the same value, though they will differ for small n." (Pp. 447.)

" Reichenbach does mention simplicity as a ground for choosing the straight rule, but this is surely a very weak ground and is, in any case, separate from his "pragmatic justification." Cf. Reichenbach, op. cit., pp. 447.

"Ibid., p. 447.

${ }^{6}$ Black, op. cit., pp. 195, 208.

${ }^{7}$ Ibid., pp. 191-208.

${ }^{8}$ Rudolf Carnap, The Continuum of Inductive Methods (Chicago: University of Chicago Press, 1950).

'John Lenz, "Carnap on Defining 'Degree of Confirmation," "Philosophy of Science, July 1956, pp. 230-36. I have in this article criticized Camap's answer to this problem, but it is to Carnap's great credit that he sees the problem very clearly.

${ }^{10}$ Black, op. cit., pp. 168-73.

II Ibid., pp. 170-71.

${ }^{22}$ Hans Reichenbach, op. cit., p. 446.

${ }^{18}$ Ibid., pp. 461.69.

\section{Ontological Commitments}

\author{
by WILLIAM P. ALSTON
}

UNIVERSITY OF MICHIGAN

DuRING the past half-century many philosophers have occupied themselves with translating one linguistic expression into another, or with providing general schema for such translations. And some of them, sensitive to charges of engaging in parlor games during working hours, have tried, in various ways, to exhibit the serious value of such activities. I want to consider one very popular sort of philosophic translation-the sort which goes from sentences of the form 'There are P's' (or from other sentences which obviously imply sentences of this form, such as 'The $P$ is $R$ ') to sentences 
of some other form. And I want to consider one very common explanation of the point of such translations-viz., that they enable us to avoid "ontological commitments" to P's. It will be my contention that this explanation is basically confused, and that it only succeeds in raising a dust which obstructs our view of the real point of such translations.

Let's begin by considering an example from Morton White's recent book, Toward Reunion in Philosophy. ${ }^{1} \mathrm{He}$ is speaking of the sentences 'There is a difference in age between John and Tom' and 'There is a possibility that James will come.'

"How, then, can we clarify these puzzling sentences and yet avoid the unwelcome conclusion that there are possibilities and age-differences in our universe ...

"In the case of 'There is a difference in age between John and Tom,' we might begin by saying that we understand the relational predicate is as old as' and that we test statements of the form ' $x$ is as old as $y$ ' without having to see that $\mathrm{x}$ has some queer thing called an age, that $\mathrm{y}$ has one, and that these ages are identical. In that event, the belief of the ordinary man that there is a difference in age between John and Tom would be rendered in language that is not misleading by saying instead, simply, 'It is not the case that John is as old as Tom.' We might offer an analogous translation of 'There is a possibility that James will come' in which we replace it by some statement about the statement 'James will come, for example by the statement that this statement is not certainly false. . . . what we have done is to show that we need not assert the existence of age-differences or the existence of possibilities in communicating what we want to communicate." (Pp. 68-69.)

Here are several philosophically interesting translations of this sort (which I shall call 'existential reduction'):

1. There is a possibility that James will come.

2. The statement that James will come is not certainly false.

3. There is a meaning which can be given to his remarks.

4. His remarks can be understood in a certain way.

5. There are many virtues which he lacks.

6. He might conceivably be much more virtuous than he is.

7. There are facts which render your position untenable.

8. Your position is untenable in the light of the evidence.

Now it is puzzling to me that anyone should claim that these translations "show that we need not assert the existence of" possibilities, meanings, virtues, and facts "in communicating what we want to communicate." For if the translation of (1) into (2), for example, is adequate, then they 
are normally used to make the same assertion. In uttering (2) we would be making the same assertion as we would make if we uttered (1), i.e., the assertion that there is a possibility that James will come. And so we would be asserting that there is a possibility (committing ourselves to the existence of a possibility) just as much by using (2) as by using (1). If, on the other hand, the translation is not adequate, it has not been shown that we can, by uttering (2), communicate what we wanted to communicate when we uttered (1). Hence the point of the translation cannot be put in terms of some assertion or commitment from which it saves us.

This dilemma has more than a passing resemblance to the "paradox of analysis," which was extensively discussed a short while ago. (If $\mathrm{x}$ is adequately analyzable as $y$, then ' $x$ ' and ' $y$ ' must be synonymous. But if so, how can we convey any information by saying ' $x$ is $y$. ') Some philosophers attempted (unsuccessfully in my opinion) to resolve the paradox of analysis by pointing out differences between the meanings of ' $x$ ' and ' $y$ ' which were sufficient to make the analysis informative, but not so great so to render it invalid. Similar gambits might be tried here, although the omens are no more favorable than before.

A. It may be said that (1) differs from (2) only in carrying an imputation of 'ultimate reality' to possibilities, in implying that possibilities are among the 'ultimate furniture of the universe.' Thus in replacing (1) with (2) we continue to say everything we have any need or right to say, sloughing off only the groundless, and gratuitous, attribution of ultimate reality.

Before we can accept this account we must understand what is meant by 'ultimate reality' and this is not altogether easy. What can be meant by 'taking possibilities to be ultimately real,' other than simply asserting, seriously and with full awareness of what we are doing, that, for example, there is a possibility that James will come? And this can be done by the use of (2) as well as (1). ${ }^{2}$ But suppose that some meaning can be given to the phrase 'ultimate reality,' such that (2) does not carry with it an implication of the ultimate reality of possibilities. It is still worthy of note that no one has given adequate reason for the supposition that (1), as ordinarily used, carries any such implication either. What evidence is there that the ordinary man in uttering (1), or the scientist in uttering a sentence like 'There are fourteen electrons in this atom,' is asserting the ultimate reality of possibilities or electrons in any sense which goes beyond the serious and deliberate use of these sentences to make assertions? Of course a philosopher who utters such sentences as 'Possibilities are ultimately real,' 'Possibilities are objective entities,' etc., is asserting the ultimate reality of possibilities if anyone ever is. But does that justify us in saying that he is making the same assertion when he utters (1)? Well, 
perhaps the fact that he uses these queer sentences is an indication that his use of (1) carries a metaphysical implication. But if it does then precisely for that reason he will not admit that by using (2) he can just as well say what he wanted to say when he used (1). This is our problem all over again. Wherever (1), unlike (2), does carry a metaphysical force, the translation is not adequate. Thus the analysis would only have the virtue of showing us that we could say what we want to say without making an ontological commitment to possibilities, except where we want to make an ontological commitment to possibilities. In this case it would be less than a parlor game.

B. Alternatively, admitting that talk of 'ultimate reality' is unclear, or even unintelligible, one might locate the value of the analysis in the dissolution of this unclarity, i.e., in the fact that (2) says everything that is clearly said by (1) but without these confused suggestions of ultimate reality. But does (1) as ordinarily used carry such suggestions? Even if it does and even if this account is substantially correct, it offers no aid and comfort to the ontological interpretation. The ontological interpretation presupposes that there is an activity called admitting the (ultimate) existence of possibilities' which we might or might not perform, and the performance or nonperformance of which hinges on whether we employ (1) or (2) to say what we want to say (or on whether we use (1) with or without the realization that it can be translated by (2)). But to say that phrases like 'ultimate existence' are unintelligible is to say that we can't understand what such an activity would be, or what it would be like to perform it, and so are unable to specify what admission it is from which the translation saves us. In other words, on the present account, what the translation enables us to avoid is not certain commitments or assertions, but certain confusions. This clue will be taken up later. But first-back to the ontologist.

These moves have not proved fruitful. But there is indeed one thing, not yet explicitly mentioned, which the translation of (1) into (2) does enable us to avoid, and that is the sentence, (1). More generally the schema of which this translation is an instance enables us to say what we want to say without having to use any sentences of this form, i.e., any sentence beginning with 'There is (are),' followed by 'a possibility ...' 'the possibility .. .' ('possibilities ...' 'some possibilities . . '), etc. And the hard-pressed ontologist may make a stand here by roundly declaring that the ability to avoid sentences of this form is what he means by avoiding an ontological commitment. That is, he will define 'ontological commitment to possibilities' as the inability to say what we want to say without using such sentences. 
To be at all plausible this definition will have to be patched up. As it stands, we could avoid an ontological commitment to possibilities simply by introducing a new word as synonymous with 'there is,' or with 'possibility.' This makes the game too easy. The rules can be tightened by requiring that the restatement consist only of existing expressions with their established meanings. But that won't be enough. No one could consider the translation of (1) into 'The possibility exists that James will come' to constitute an evasion of an ontological commitment. The trouble is that there are a number of expressions in common use ('. . . exists,' 'some ...') which do essentially the same job as 'there is'; let us speak of these expressions as having an explicitly existential force. ${ }^{3}$ The sort of translation we are trying to specify is a translation from a sentence which contains one of these expressions, along with the crucial predicate terms, into a sentence which does not. Taking account of this let us restate the definition of ontological commitment as follows:

I. One is ontologically committed to P's if and only if he is unable to say what he wants to say without using a sentence of the form "There is (are) a $\mathrm{P}$... (the $\mathrm{P}$. . ., $\mathrm{P}$ 's . . . etc.)' or some other sentence which deviates from this form only by replacing 'there is' by some other expression with explicit existential force or by replacing ' $\mathrm{P}$ ' by a synonym (together with such grammatical changes as are required by these replacements, as in the change from 'There are some lions in this country' to 'Lions exist in this country'). ${ }^{4}$

By a not so fortuitous circumstance this criterion is substantially equivalent to Quine's famous criterion for ontological commitment.

II. We are convicted of a particular ontological presupposition if, and only if, the alleged presuppositum has to be reckoned among the entities over which our variables range in order to render one of our affirmations true. (From a Logical Point of View, p. 13.) ${ }^{5}$

An entity is assumed by a theory if and only if it must be counted among the values of the variables in order that the statements affirmed in the theory be true. (Ibid., p. 103.)

The equivalence can be seen as follows. The variables of a theory must range over $\mathrm{P}^{\prime}$ 's in order to make the affirmations of that theory true if and only if one of those affirmations is either 'There are P's' or some statement which implies 'There are P's,' such as 'There are R's and all R's are P's.' Of course Quine's criterion applies explicitly only to "theories" which are in quantificational form. But he himself points out that the criterion is applicable to theories otherwise expressed provided they can be translated into this form. And I see no reason why any English sentence beginning 
with 'there is' cannot be translated into one beginning ' $\exists x$.' In fact II can be viewed as a narrower version of $I$, since ' $\exists \mathrm{x}^{\prime}$ ' is one of the expressions which does essentially the same job as 'there is.' Hence although the following remarks will be explicitly directed, for the most part, to I, they will, I believe, apply equally to II.

Do we, then, adequately bring out the merits of existential reduction by saying that it enables us to avoid "ontological commitments," in the sense specified by these criteria? These criteria do point up the way in which such translations enable us to cut down the number of sentences of an explicitly existential form which we use (or to reduce the range of our variables). And in certain contexts this may be a virtue. There may be desires, widespread among logicians, which are satisfied by such reductions. And for certain purposes of theory construction or formalization it might be desirable to have as narrow a range of variable substitutions as possible. But it is at best misleading, and at worst flatly incorrect, to record this achievement by saying that we have avoided making an ontological commitment to P's, or avoided asserting the existence of P's. For the achievement consists, to return to our chief example, in finding some other sentence which can be used to make the same statement which one had been making in uttering ( 1 ). And, in any ordinary sense of these terms, whether a man admits (asserts) the existence of possibilities depends on what statement he makes, not on what sentence he uses to make that statement. One admits that possibilities exist whenever he assertorially utters (1), or any other sentence which means the same (would ordinarily be used to make the same statement). It is a question of what he says, not of how he says it. Hence he cannot repudiate his admission by simply changing his words. ${ }^{6}$

A man who was afraid of policemen would be reassured if he were convinced that there are no policemen. But he would not be reassured if he were convinced that one could express all one's beliefs in a language which took not policemen, but rather policemanship, as values of variables (that one could avoid locutions like 'There is a policeman around the corner' in favor of 'Policemanship is exemplified around the corner'). Nor could we convince a scientist that the assumption of the existence of electrons can be dispensed with, simply by providing a way of translating every sentence of the form ' $(\exists x)$ ( $x$ is an electron ... )' into another sentence which has the same meaning but which does not require variables to range over electrons, though he would be convinced if we could provide a theory which did the same jobs as his electronic theory but contained no individual sentences which were synonymous with his sentences asserting the existence of electrons. That is, in any context where questions of existence arise the 
problem is whether or not we shall assert that so-and-so exists, not whether we shall choose some particular way of making this assertion. This means that assertion of existence, commitment to existence, etc., does not consist in the inflexible preference for one verbal formulation over any other, however gratifying such preferences may be to logicians, and that the use of the phrase 'ontological commitment' here is unjustifiable and misleading.

Of course Quine could say that the notational question is what he is interested in and that, ordinary usage be damned, this is what he is using 'ontological commitment' to mean. But the whole point of his using 'ontological commitment' for this purpose rather than some other phrase (and the associated use of cognate expressions like 'believe in the existence of,' 'countenance abstract entities,' etc.) is to associate, or identify, the terminological problem with existential problems as they are ordinarily conceived, and so transfer to the former the interest and importance which attaches to the latter. Otherwise why present the values of variables formula as a criterion for 'ontological commitment' instead of just as something which is interesting in its own right? The fact that Quine intends his criterion to be more than just notational in import is further brought out by (1) his insistence that ontological questions (as he formulates them) are not different in kind from scientific questions; (2) his use of considerations other than notational convenience (queerness, unobservability) in deciding what values of variables it might be desirable to avoid.

Thus in the last analysis the ontological interpretation can offer no rationale of existential reduction other than the notational convenience attaching to the avoidance of certain verbal forms. But surely this sort of analysis has more significance than that. To get at its significance I shall relapse for a moment into ontological terminology and ask the hitherto neglected question 'Why should anyone wish to avoid an ontological commitment to, for example, possibilities?' More generally, why do the ontological analysts bend their efforts toward escaping from ontological commitments to "abstract entities" (attributes, classes, possibilities, meanings, facts, etc.) rather than to "concrete entities" (physical objects, events, persons, etc.). The reasons most commonly cited are these (Ockham's razor is not relevant here, since the question is not why we should ever try to avoid ontological commitments, but why we should aim at paring off abstract rather than concrete entities):

1. Possibilities, etc., are queer.

2. Possibilities, etc., are obscure in their nature.

3. Possibilities, etc., are unobservable (there is no empirical reason for supposing that there are any such things).

Obviously these reasons are not expressed very clearly. To say that a 
possibility is queer or obscure is no argument against its existence; on the contrary it is a conclusive argument for its existence. Possession of any characteristic entails, or presupposes, existence. And the unobservability of possibilities is not a matter of fact like the unobservability of mangoes on my desk or of unicorns. It is rather that we can't understand what it would be like to empirically observe a possibility.

These complaints are captious. But they do show that the objections to abstract entities would be more precisely expressed by talking not about possibilities, but about what people say about possibilities. It is because people sometimes say (and ask) such queer and obscure things about possibilities, and talk about them in empirically untestable ways, that our ontological analysts are so loath to "make an ontological commitment to possibilities," i.e., are so loath to use a sentence like (1). More specifically, the tendency to shy away from sentences like ( 1 ) is due to the fact that people who attach a great deal of importance to such sentences (and resist replacing them with sentences of other forms) are liable to:

1. Ask such puzzling questions as 'Are possibilities eternal?' 'Can a proposition be immediately intuited?' 'What are the parts of a fact?' 'Are there negative facts as well as positive ones?'

2. Propound 'theories' which are unintelligible, or at least such that we cannot find any relevant arguments for or against them. For example, 'Possibilities contain in their essence a reference to actuality' 'Every true statement corresponds with a fact' 'Attributes have an existence independent of their exemplifications' 'Meanings are known by intuition.'

3. Take the existence (or ultimate existence) of such entities as problematic, subject to proof or disproof, even after ordinary sentences like (1) have been accepted, without giving an intelligible account of the difference between asserting ultimate existence in this problematic sense and simply assenting to the ordinary sentence.

But if (1) and (2) are synonymous, why should (1) and not (2) suffer this abuse, and how can the replacement of (1) with (2) alleviate the situation? It is at this point that the real virtue of this sort of translation can be seen. Consider the following parallels:

There is a possibility that James will come

There is a meaning which can be given to his words

There are many virtues which he lacks
There is a fruit that James will eat

There is a chair which can be given to his aunt

There are many articles of clothing which he lacks

In each case the strong verbal similarity provides a temptation to assimilate 
the two sorts of existents, i.e., to suppose that we can talk of one in the same way as the other. Since chairs have spatial locations, we are apt to ask about the (ontological) locus of meanings. (See Whitehead on God as the locus of "eternal objects.") Physical objects like chairs and fruits consist of parts which can be specified, unless they are atomic; and so we are led into asking whether facts or propositions are atomic, and if not what their parts are like. ${ }^{7}$ Since this is a story which has been often, and ably, told in the recent literature, I shall not elaborate it further. The moral to be drawn here is that the only "ontological commitment" to possibilities which there is any reason to consider undesirable is the tendency to talk about possibilities in inappropriate ways ("category mistakes").

It is the seductive grammatical family likenesses of sentences like (1) which render them objectionable, not any assertion of the existence of possibilities they carry with them, in any intelligible sense of that term. And the point of translating (1) into (2) lies in the fact that once anyone sees that what he says when he uses (1) can be just as well said by using (2), the power of the grammatical lure will be broken. To see that one can say that there is a possibility that James will come, by using either of two sentences of quite different grammatical forms, is to see that possibilities do not have to be talked about in the way which would be suggested by either of these forms, and hence that one does not have to ask about possibilities the same sort of questions one asks about chairs. To put it in a rather dangerous way, he sees that possibilities do not exist in the same way as chairs. Of course the translation doesn't prove that the same questions cannot be asked about possibilities and about chairs. It is rather that the realization that the translation holds relieves us of the compulsion to ask these questions about possibilities in spite of the impossibility of really making sense of them.

Thus we can make explicit the virtues of existential reduction, taking account of the (unconfused) motives which have led people to perform it, without having to say what we have seen to be untenable-viz., that it enables us to avoid admitting the existence of something.

This way of looking at the matter should also free us from the supposition, which the ontological account might suggest, that when we utter ( 1 ) we are inevitably saying something false, at least if we haven't seen that it can be translated into (2), whereas we wouldn't be subject to any such danger in using (2), even if we didn't realize that it is translatable into (1). This gives rise to the idea that there is something inherently objectionable about (1), a sort of ontological taint. But when we see that the point of the translation is the neutralizing of tendencies to confusions, we see that the problem is essentially a strategic one. One is not necessarily misled by 
(1), with or without a translation, nor is one necessarily safe from confusion by using (2). The translation is a device for removing confusions wherever they arise. They usually arise in connection with (1), in which case we show that (2) can be used to say the same thing; but the reverse procedure might conceivably be useful. Just as no sentence is necessarily misleading, so none is guaranteed, by its form, to be used without confusion. The supposition to the contrary is one of the unfortunate effects of philosophic preoccupation with artificial languages.

Received May 15, 1957

\title{
NOTES
}

${ }^{1}$ Cambridge, Mass.: Harvard University Press, 1956.

'One sometimes suspects that it is some peculiar solemnity attaching to 'There is' (and especially to ' $\mathrm{x}$ ') which leads philosophers to give sentences like (1) a metaphysi- $\exists$ cal import not imputed to sentences like (2).

${ }^{3}$ The boundaries of this group are not precise. For example, there would be controversy over whether 'some . . .' belongs here.

${ }^{4}$ This criterion could be further made precise by making more explicit the scope of the 'etc.' Not any phrase containing 'possibility' can be combined with a 'there is' to produce a sentence which would normally be used to assert the existence of possibilities. Consider, for example, 'There is a man who is holding some good possibilities open for you.' More generally, what is required is that ' $\mathrm{P}$ ' falls within the scope of the existential expression. This of course needs further clarification.

${ }^{5}$ Cambridge, Mass.: Harvard University Press, 1953.

${ }^{\circ}$ Can there be a confusion of sentence and statement lurking in this criterion of 'ontological commitment'?

'There are many reasons why the grammatical similarity, which is symmetrical, leads to confusions on the lefthand rather than the righthand side. The most important ones are these two: (1) We have, in our language a rich repertoire of locutions for talking about chairs, fruits, etc., whereas there are comparatively few ways of talking properly about possibilities, meanings, etc. Thus the pull is into the vacuum on the left. (2) Our tendency to picture everything we talk about entails a tendency to construe the unpicturable abstracta on the model of the picturable concreta.

\section{Lazerowitz's Verbalism}

\author{
by L. O. KATTSOFF
}

UNIVERSITY OF NORTH CAROLINA

IN 1942, Professor Lazerowitz contributed to the volume on G. E. Moore edited by Paul Schilpp a chapter entitled "Moore's Paradox." Its recent republication as Chapter 1 in The Structure of Metaphysics (New York: Humanities Press, 1956) indicates that he considers what he said there of 